First online: 7 July 2017

\title{
Chronographic Allocation Techniques for Construction Projects
}

\author{
Adel Francis ${ }^{* 1}$ \\ Department of Construction Engineering, École de technologie supérieure, \\ 1100 Notre-Dame Street West, Montreal, QC H3C 1K3, Canada \\ *1adel.francis@etsmtl.ca
}

\begin{abstract}
The literature is abundant in terms of research on resource management and optimization methods. Many deterministic, probabilistic and heuristic methods propose how to use resources efficiently. However, this paper discusses allocation techniques, i.e. how to technically allocate resources to activities rather than how to use resources efficiently. Though this subject is thoroughly covered by commercial scheduling software, it is generally absent from the literature. This paper compares the proposed Chronographic Modeling with the methods employed by commercial scheduling software. The new allocation methodology defines three attribute methods: complete attribute, attribute by segment and attribute by scale. Proposing internal divisions, as well as internal, external, vertical and horizontal scales, allows planners to create all kinds of attributes, from bulk allocation to any type of external and internal scale attribute. The links between scales could also show interactions between different measurement units and offer several types of durations, quantities and costs for increased flexibility and resolution of the limitations of existing methods. This paper adds to the body of knowledge by introducing a complete and realistic allocation methodology for construction project scheduling.
\end{abstract}

Keywords- Chronographic; Precedence, Modeling; Attribute; Resource Scheduling; Resource Assignment; Scheduling Software; Microsoft Project; Primavera; Tilos; Construction Management; Project Planning

\section{INTRODUCTION}

The efficient use of resources is a prerequisite for project success and generally, managers make great efforts to manage and optimize resources. The literature is abundant in terms of resource management research, from the simple application of a Monte Carlo simulation to the use of linear programming, genetic algorithms, ant colonies, fuzzy set theory and even artificial intelligence. Many deterministic, probabilistic and heuristic methods are then employed. Recent studies, such as [1-3] recommend different algorithms as a solution to resource allocation and leveling problems. Asgari et al. [1] proposed a multiple decision-maker resource-leveling models and stated cooperative game theory as an appropriate framework for analyzing joint resource management in construction. Moreover, Zhou et al. [5] suggested integrating mathematical algorithms with 4D models to simulate detailed construction activities for resource scheduling. Ashuri and Tavakolan [5] presented a mathematical formulation of time-cost-resource optimization (TCRO) problems and designed a model to solve TCRO problems. Using simulation techniques, Chen et al. [7] proposed an intelligent scheduling system (ISS) to distribute resources and assign different levels of priorities to different activities. Min and Einstein [8] employed simulation techniques to resource/space availability to develop a resource model applicable in Tunnel construction. Siu et al. [9] proposed resourcebased scheduling as a solution to the supply-demand matching problem. Zhang et al. [10] considered the learning effect while allocating resources in repetitive construction projects.

However, this paper discusses allocation techniques, i.e. how to allocate resources to activities. This subject is thoroughly covered by commercial scheduling software and mostly absent from the literature. The literature discusses resource management and optimization methods that is, how to use resources efficiently rather than how to technically allocate resources to activities. It is, therefore, necessary to compare the proposed approach with the methods employed by scheduling software.

This paper adds to the body of knowledge by introducing a more complete allocation methodology for project scheduling. The objective of the paper is to propose a complete allocation methodology compatible with the Chronographic Modeling [1115].

This new allocation methodology uses three attribute allocation methods: complete attribute, attribute by segment and attribute by scale. Proposing internal divisions, as well as internal and external scales, allows planners to create all kinds of attributes for increased flexibility. Effective attribute methods should permit planners to assign any physical type to any other. Resources can be allocated to activities (to set production rate) or to working areas (to define site occupation). Activities can also be allocated to working places (to find out where these activities will be carried out) or to resources (to define the workload of individuals and teams). Existing methods and software only address the allocation of resources to activities. However, managing resources regardless of their location is inefficient and may lead to misleading schedules. Even if resources are available, they cannot be used beyond the capacity of workspaces. Otherwise, workspace congestion will 
negatively affect the movement of people and materials and may reduce productivity at construction sites. Despite this fact, this paper will only attribute resources to activities with the aim of comparing existing methods employed by commercial software. Future studies will then be oriented to model and manage all types of allocations, such as activities, human resources, materials or work locations to any other type, to model complex projects and to show how to optimize the projects using these different types of allocations.

The remainder of this paper is structured as follows: Section II discusses resource allocation using existing project scheduling software, Section III represents the Chronographical Modeling, Section IV explains attribute methods in detail according to the chronographic logic system, and Section V shows two application examples of the proposed methodology.

\section{RESOURCE ALLOCATION USING EXISTING PROJECT SCHEDULING SOFTWARE}

To better explain existing allocation methods, this section shows the allocation of resources using the three most common software programs in the construction industry in North America: Microsoft Project, Primavera, and TILOS. Microsoft Project and Primavera model the schedule using a Gantt chart with a horizontal time-scale axis and plot each new activity in a new data row. Critical path calculation for these two programs uses precedence logic, with four types of relationships. TILOS presents linear diagram methods graphically, with two scaled axes indicating time and units.

All three of these scheduling software programs use their terminology and logic for allocating resources to activities. This section compare these three programs in terms of their types of resources, activities, and if necessary, their allocation logic.

\section{A. Comparison of Resource Types Between Microsoft Project, Primavera, and TILOS}

Each software program has its way of allocating resources and defining resource types. To illustrate the differences between the various types of resources with each of these programs, Table 1 compares permanent resources, such as labor and equipment, with consumable resources, such as materials. Permanent resources are measured in units of time, while consumable resources are measured in units other than time, such as cubic meters.

In addition, Microsoft Project and TILOS offer a third type of resource. Microsoft Project has a cost type that covers fixedprice contracts, while TILOS has a component type that simply groups permanent and consumable resources. In Primavera, the permanent resources are divided into two subgroups, labor, and non-labor (resources that do not perform labor, such as equipment).

TABLE 1 RESOURCE TYPES WITH MICROSOFT PROJECT, PRIMAVERA AND TILOS

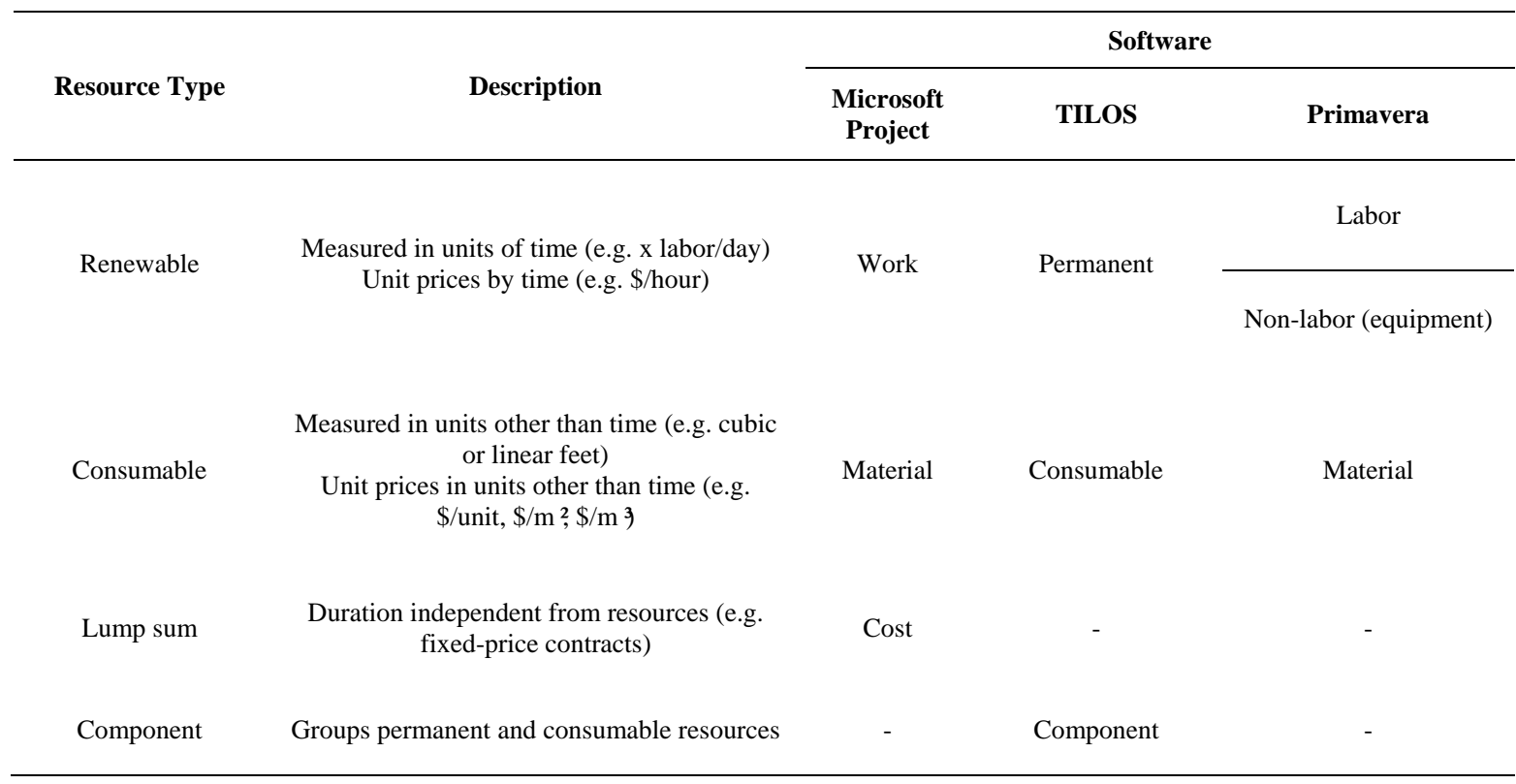

The way each program creates and manages resources is also different. Microsoft Project and Primavera allow planners to define effort and a maximum capacity for each resource, assign different schedules for each resource, define overtime costs and assign different hourly rates for the same resource. Microsoft Project also lets users define a cost of use (cost/use) and use the "Accrue at" function to assign the cost to the start date, end date or as a prorated activity duration. Primavera defines resource/cost distribution as a linear or non-linear curve to specify how resource units or costs are distributed over the duration of activity.

\section{B. Task Types and Allocation Management with Microsoft Project}

With Microsoft Project, planners can manage activity duration using a property called Task Type. Microsoft Project offers 
three variables to define tasks types:

- Unit, which designates the number of resources per unit of time (e.g. 5 people per day)

- Duration, which designates the total time to perform an activity (e.g. 5 days)

- Work, which defines the total amount of resources needed to execute the activity (e.g. 30 days of labor)

The relationship between these three variables is illustrated using the following formula:

$$
\text { Work }=\text { Units } \mathrm{x} \text { Duration }
$$

For each activity, Microsoft Project allows planners to secure one of these three task types by indicating which variable should not change automatically. The following paragraphs demonstrate the impact of the task type on resource and duration management:

- Fixed Units: Indicates that the number of resources must remain constant regardless of any changes in the activity duration or work.

- Fixed Duration: Indicates that the activity duration must remain constant regardless of any changes in the units or work.

- Fixed Work: Indicates that the amount of work must remain constant regardless of any changes in the activity duration or units.

The Effort-driven property, which specifies that the activity's total work will be fixed at its current value, is added to these. Adding or removing resources reduces or lengthens the duration of the activity while the work required to complete the activity remains unchanged.

The Effort-driven property takes effect only after the initial allocation. Also, it is not enough to either increase or decrease the capacity of existing resources; planners must add new resources.

The author believes that this methodology only partially meets planners' needs and has the following shortcomings.

- Microsoft Project does not allow the three variables (units, time and work) to be fixed simultaneously; at least one variable must change automatically. This is inappropriate in certain situations, as demonstrated in the below examples. In some cases, planners may want to fix all three variables. This means that no automatic calculation occurs by increasing or decreasing any variables.

- Planners want to make an indicative allocation to check the contractor's ability to complete the work on time. In this case, planners would input the units without any need to calculate any work or recalculate the duration.

- During the planning phase in which the input data must remain unchanged and must correspond with the estimate data, planners would input the work without any need to calculate any units or recalculate the duration.

- The software determines a logic that may not match all needs. As an example of fixed units, if one changes the work, Microsoft Project recalculates duration and leaves the units unchanged without asking which variable to set.

- The Effort-driven property applies only when adding or removing a new type of resource. This means when allocating two carpenters to an activity and then decide to add a third one, Effort-driven will not take effect and the work will increase. However, if a carpenter helper is add to the same two carpenters, the amount of work remains unchanged, and the activity duration will decrease by a third, which is illogical.

\section{Duration Types and Allocation Management with Primavera}

With Primavera, activity duration depends on resource use. Planners can manage duration with a property called Activity Duration Type. Primavera offers four types of activity durations.

- Fixed Units: The activity units remain constant regardless of the duration value or resource units per period. This type could be applied when the total amount of work is fixed.

- Fixed Duration \& Units: The activity duration and total amount of work remain constant regardless of the value of units per time.

- Fixed Units/Time: The resource units per time remain constant regardless of the value of the activity duration or total amount of work. This type is used when an activity has a fixed number of resources per period.

- Fixed Duration \& Units/Time: The activity duration and resource units per period remain constant, and the total or remaining amount of work changes.

This methodology provides more flexibility than Microsoft Project. However, Primavera does not allow the three variables (time, units and units/time) to be fixed simultaneously; at least one must change automatically.

The left column of the following Table 2 shows the four activity duration types in Primavera, and the right column shows their equivalents in Microsoft Project. It should be mentioned that despite the apparent equivalence between Fixed Duration \& Units and Fixed Duration and Effort-driven, the operation and obtained results from these two types of activities are clearly different. 
TABLE 2 ACTIVITY DURATION TYPES IN PRIMAVERA AND THEIR EQUIVALENTS IN MICROSOFT PROJECT

\begin{tabular}{cc}
$\begin{array}{c}\text { Activity Duration Type } \\
\text { in Primavera }\end{array}$ & $\begin{array}{c}\text { Task Type } \\
\text { in Microsoft Project }\end{array}$ \\
\hline Fixed Units & Fixed Work \\
Fixed Duration \& Units & Fixed Duration and Effort-driven \\
Fixed Units/Time & Fixed Units \\
Fixed Duration \& Units/Time & - \\
- & Fixed Units and Effort-driven \\
\hline
\end{tabular}

\section{Allocation Calculation Models with TILOS}

In terms of calculating efforts, allocation units, and duration, TILOS provides more possibilities than the previous two programs, as shown in Table 3. The TILOS methodology is more responsive to the needs of planners, offering several calculation methods that are suitable for most cases. TILOS methodology sets the number of required resources (Allocation model), and calculates the effort depending on the activity duration. The methodology also calculates the duration of an excavation activity using excavator productivity (Units/Time [Driving task] model) and the number of trucks required based on the capacity. Moreover, if the manual calculation method is selected, TILOS does not apply any automatic calculation methods. In the latter case, all changes must be made manually.

TABLE 3 CALCULATION MODEL FOR PERMANENT RESOURCES WITH TILOS

\begin{tabular}{|c|c|c|}
\hline Model & Input & Calculation \\
\hline Allocation & Number of resources & Effort $=$ Input $\mathrm{x}$ Duration \\
\hline Effort/Unit & Effort required per unit of work (e.g. $1 \mathrm{~h} / \mathrm{m}^{3}$ ) & Effort = Input $\mathrm{x}$ Quantity \\
\hline $\begin{array}{l}\text { Hours, Days or } \\
\text { Months }\end{array}$ & Number of hours, days or months & Effort $=$ Input \\
\hline Units/Time & Units of work per unit of time (e.g. $10 \mathrm{~m}^{3} / \mathrm{h}$ ) & Effort $=$ Quantity / Input \\
\hline Cargo & $\begin{array}{l}\text { Quantity of work that could be completed by one } \\
\text { resource per time period (e.g. a shovel could } \\
\text { excavate } 200 \mathrm{~m}^{3} / \text { day) }\end{array}$ & $\begin{array}{l}\text { Effort }=\text { Duration x Quantity / Input } \\
\text { This method calculates the number of } \\
\text { resources needed per period }\end{array}$ \\
\hline $\begin{array}{c}\text { Units/Time } \\
\text { (Driving Task) }\end{array}$ & $\begin{array}{c}\text { Number of work units for a resource per unit of } \\
\text { time } \\
\text { The activity duration depends on resource } \\
\text { productivity }\end{array}$ & $\begin{array}{c}\text { Effort }=\text { Allocation (Input) } \times \text { Duration } \\
\text { Work Rate }=\text { Sum of Units } / \text { Time } \times \Sigma \\
\text { Allocation }\end{array}$ \\
\hline
\end{tabular}

\section{CHRONOGRAPHIC LOGIC}

With the Chronographic Logic system, physical entities (by default, activities) can have one or more internal divisions related to the internal or external scales. Traditional relationships (e.g. finish-to-start and start-to-start, finish-to-start and startto-finish) are then replaced by point-to-point relationships to connect activities at any point [6].

This paper discusses different ways of assigning attributes, as proposed by the Chronographic Modeling. As previously stated in this paper, we are only going to attribute resources to activities, with the aim of comparing these methods to existing methods employed by commercial software.

\section{THE ATTRIBUTE METHODS ACCORDING TO THE CHRONOGRAPHIC LOGIC SYSTEM}

This section will use the example shown below in Table 4 for resource allocation purposes. This example concerns a castin-place concrete activity for linear footings whose dimensions are $250 \mathrm{~mm}$ high and $500 \mathrm{~mm}$ wide. These foundations are part of a fence erection project with a length of $5120 \mathrm{~m}$. This activity is planned through two allocation examples. 
1. The first allocation example uses an activity with no internal divisions. The total quantity of concrete is $640 \mathrm{~m}^{3}(5120$ $\mathrm{m} \times 0.25 \mathrm{~m} \times 0.50 \mathrm{~m})$. The estimated resources required to accomplish the activity are 40 labor days and 40 hours per pump. The production rate is $160 \mathrm{~m}^{3}$ of concrete per day, and the duration is 4 days.

2. The second allocation example uses an activity with two internal divisions. The first section covers the first $2160 \mathrm{~m}$ with a production rate of $180 \mathrm{~m}^{3}$ of concrete per day. This results in a total concrete quantity of $270 \mathrm{~m}^{3}$ and a duration of 1.5 days. This first section requires 15 labor days and 15 hours per pump. The second section covers the remaining $2960 \mathrm{~m}$. This section has a production rate of $148 \mathrm{~m}^{3}$ of concrete per day. Thus, the total amount of concrete is $370 \mathrm{~m}^{3}$, and the duration is 2.5 days. The second section requires 25 labor days and 25 hours per pump.

TABLE 4 DATA FOR THE EXAMPLES

\begin{tabular}{|c|c|c|c|c|c|c|c|c|c|c|c|}
\hline & \multicolumn{5}{|c|}{ 1rst allocation example } & \multicolumn{6}{|c|}{ 2nd allocation example } \\
\hline & \multicolumn{5}{|c|}{ Total activity } & \multicolumn{3}{|c|}{1 rst segment } & \multicolumn{3}{|c|}{ 2nd segment } \\
\hline & Qty & Unit & Rate & Unit & Total & Qty & Unit & Total & Qty & Unit & Total \\
\hline Labor & 400 & hour & 50 & $\$ / h$ & $\$ 20000$ & 150 & hour & $\$ 7500$ & 250 & hour & $\$ 12500$ \\
\hline pump & 40 & hour & 200 & $\$ / h$ & $\$ 8000$ & 15 & hour & $\$ 3000$ & 25 & hour & $\$ 5000$ \\
\hline Concrete & 640 & $m^{3}$ & 200 & $\$ / \mathrm{m}^{3}$ & $\$ 128000$ & 270 & $\mathrm{~m}^{3}$ & $\$ 54000$ & 370 & $\mathrm{~m}^{3}$ & $\$ 74000$ \\
\hline & & & & & $\$ 156000$ & & & $\$ 64500$ & & & $\$ 91500$ \\
\hline
\end{tabular}

Using this example, this section discusses the different attribute types: complete attribute, attribute by segment and attribute by scale.

\section{A. Complete Attribute and Attribute by Segment}

The first two allocation methods, complete attribute, and attribute by segment, are used to prevent any automatic calculations. As their names indicate, the complete attribute is applied to the entire activity, while the by-segment attribute relates only to the designated segment. This way, each segment of the same activity can be allocated independently from the other segments. Planners may decide the amount of resources to distribute to each segment according to their vision. In this last case, only the total amount of allocated resources is fixed. The allocation by a period (or in accordance with any existing internal or external scales) is then calculated depending on the number of periods.

Table 5a shows complete and by-segment attributes for the concrete cast-in-place activity. Under both methods, the independent attribute is assigned to the principal physical entity (in this example, the activity), which means a bulk assignment of resources to the activity or segment. This table shows the concrete activity assignments of 40 labor days, 40 pump hours and $640 \mathrm{~m}^{3}$ of 30 MPA concrete. These resource amounts have been distributed manually to the two segments of the second activity.

With these two types, there are no variables or dependent attributes. This means that resources are not linked to any variable, such as activity duration or work quantity, even if these variables exist by default. The amount of resources remains unchanged, regardless of the duration or quantity of work for the activity or segment. This means that increasing or decreasing the duration or quantity of work does not change the amount of resources. Resources can only be distributed manually to execution duration, if necessary.

These two types of allocation are useful in the following two cases:

- For fixed-price contracts, the allocation is made for information purposes only to check the contractor's ability to complete the work on time, and resource leveling is not required. Work allocation on various site locations can be done by assigning specific work areas to the activity or to the subcontractor instead of to the resources. No monetary value is associated with these resources, so they are not considered in the total cost or cash flow calculation.

- During the scheduling process, the amount of resources typically comes from the estimate. Resources are allocated to the activities and should not be changed automatically during this process.

If planners decide to distribute these resources manually or according to a function (linear, ascending, trapezoidal, etc.) because of a preliminary need to level resources or work locations or to calculate the cash flow, the total amount of resources will remain unchanged while the quantity per period will be adjusted depending on the period (e.g. days).

During the leveling process, only the resources distributed over the period will be considered. Working area allocation will occur by assigning work areas to activities or resources when distributed. The total cost and cash flow can be calculated by phase. For the per period cash flow calculation, planners must indicate if the cost is assigned at the beginning, the end or distributed linearly to the activity for activities whose resources are not distributed.

During the implementation phase, planners may use the last planner's logic to update the schedule. They can distribute resources manually for the next six weeks. For automatic calculation, planners may change the allocation type of certain 
activities or segments to by-scale.

TABLE 5 COMPLETE, BY-SEGMENT AND EXTERNAL AND INTERNAL HORIZONTAL SCALE ATTRIBUTES

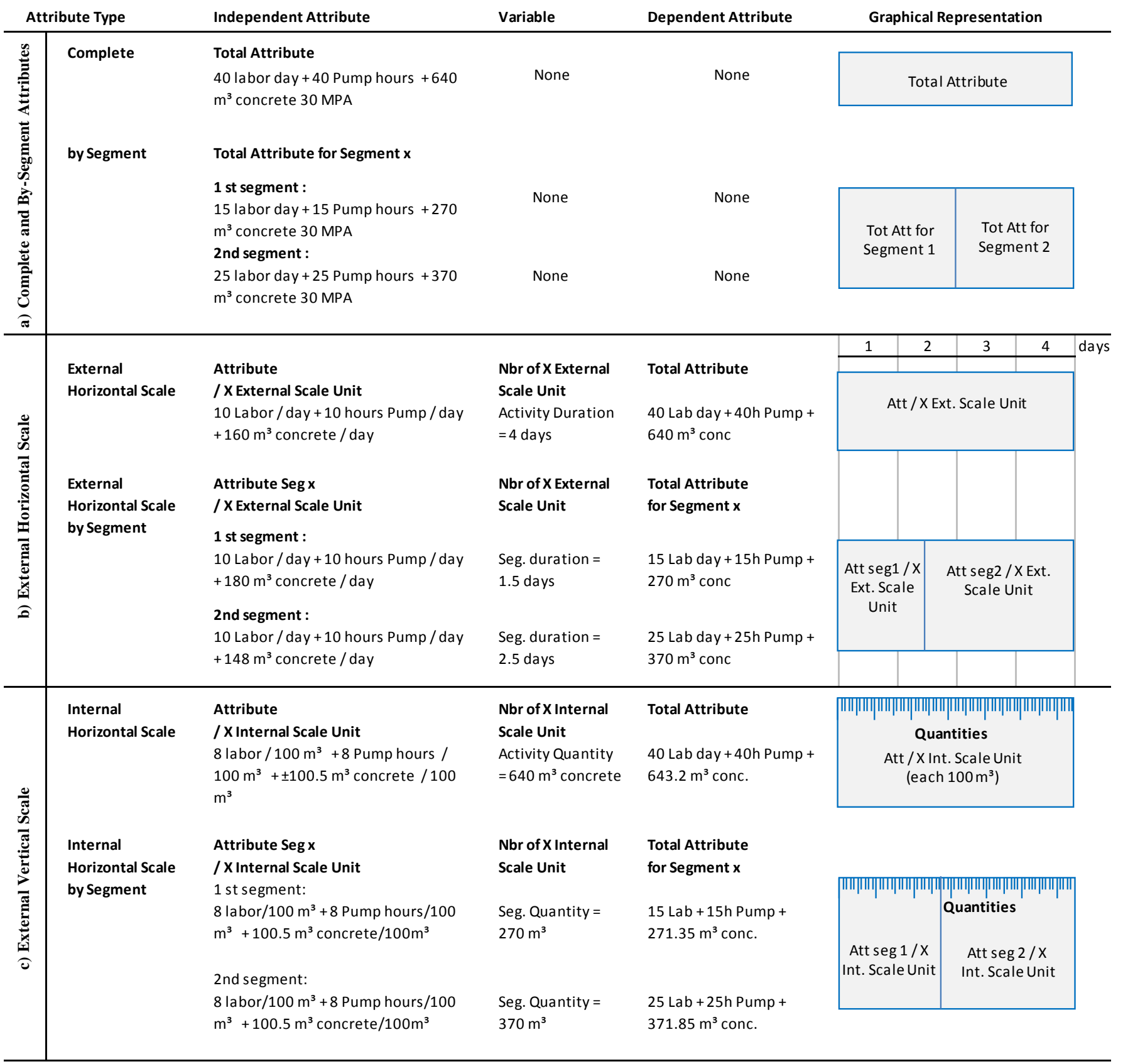

\section{B. Attribute by Scale}

Chronographic modeling proposes an internal division of activities related to internal or external scales [8]. External and internal scales can be vertical or horizontal to designate the measuring unit of the orthogonal axis system (Fig. 1a). Scales such as time, cost, work progress, quantity or risk may represent the measurement unit of the orthogonal axes. With these assignments, the automatic calculation will be based on the chosen scale.

The following subsections show the allocation methods through the external horizontal, internal horizontal, external vertical and internal vertical by-scale attribute.

\section{1) External Horizontal Scales:}

External horizontal scales may designate the measuring unit of the $\mathrm{x}$-axis for an orthogonal system. External horizontal scale measurement units should be compatible with all the main physical entities (designating the activities in the example shown in Tables 4 and 5) for the whole project. For example, time, which defines the external horizontal scale unit of the bar chart diagram, is compatible with all the main physical entities, or the activities by default. 
Table $5 \mathrm{~b}$ shows allocation methods using the external horizontal scale for the cast-in-place concrete activity for linear footings. The independent attributes (resources) are assigned to the physical entities (activities) depending on the external measurement unit for the horizontal scale (time). This means that an amount of resources is assigned to each execution day of the activity as shown in the next table: 10 labors/day +10 pump hours/day $+160 \mathrm{~m}^{3}$ concrete/day.

By adding internal divisions, the amount of human resources (labor) and equipment (pump) by external measurement unit (day) remains constant, while the total amount changes depending on the duration of the segment. In a more generic way, Attribute/X External Scale Unit represents the independent attribute, and the total attribute becomes the dependent attribute. This means that increasing or decreasing the duration of the activity or the segment will cause the total amount of resources to increase or decrease accordingly. The cost of resources is taken into account when calculating the total cost or the detailed cash flow. The duration of each segment is calculated based on its proper production rate. For the first segment, the production rate is $180 \mathrm{~m}^{3}$ of concrete per day. This production rate is $148 \mathrm{~m}^{3}$ of concrete per day for the second segment. Thus, the duration of these two segments is 1.5 days and 2.5 days respectively.

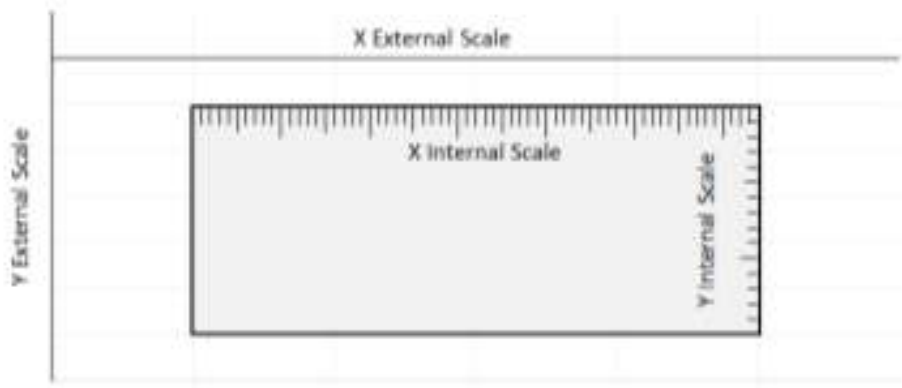

a) External and internal Scales

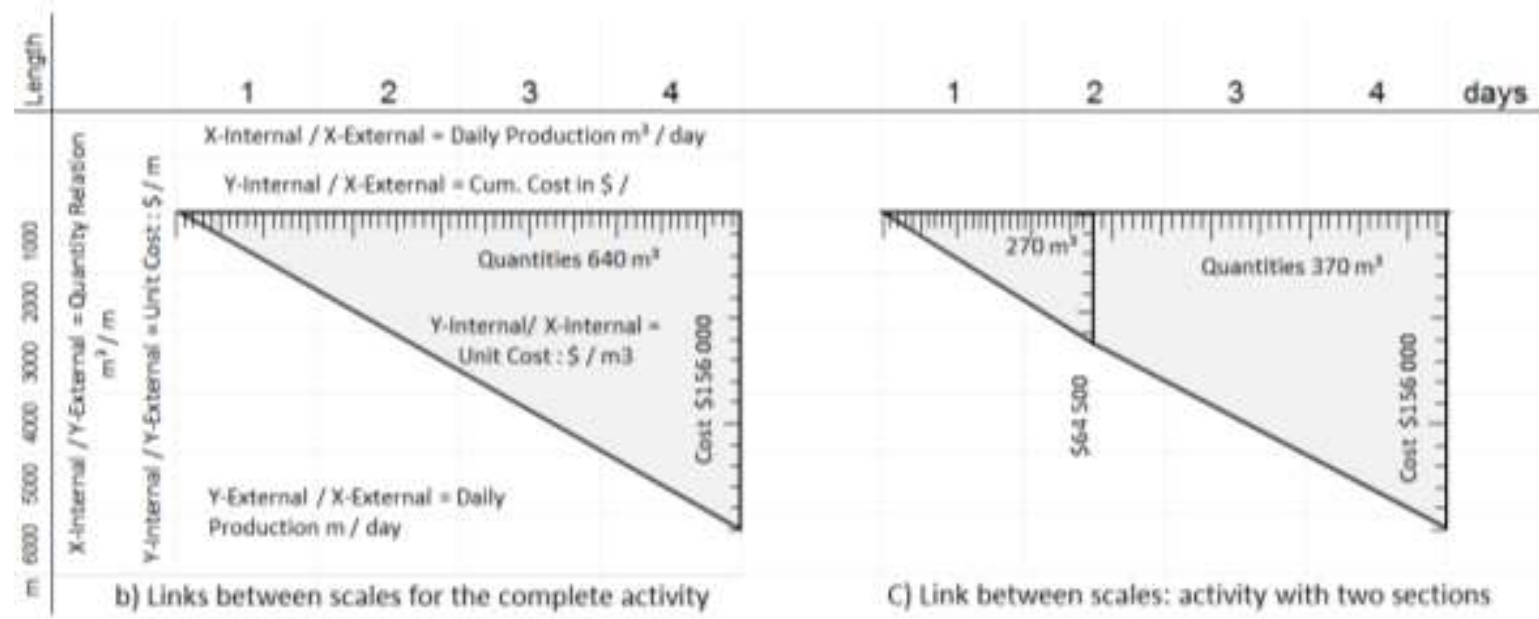

Fig. 1 External and internal scales

\section{2) Internal Horizontal Scales:}

Internal horizontal scales (Table 5c) may designate the internal measurement of physical entities. For example, activities may have an internal horizontal scale depending on the amount of work to be performed. Internal scales are specific to each main physical entity. For example, an activity (the main physical entity) can have an internal scale based on the amount of work to be performed in cubic meters, while the internal scale of a second activity in the same project can be related to the number of units to be executed.

Attribute/X Internal Scale Unit represents the independent attribute, and the total attribute becomes the dependent attribute. The independent attribute is assigned depending on the measurement unit of the internal scale. This means assigning an amount of resources to each unit of the internal horizontal scale in this case, the quantities (100 $\mathrm{m}^{3}$ of concrete). This allocation represents the independent attribute. The total amount of resources (the dependent attribute) to implement the whole activity varies depending on the executed quantity in cubic meters (the independent variable). Table 5c shows resource allocation for the cast-in-place concrete activity by assigning 8 labor $/ 100 \mathrm{~m}^{3}+8$ pump hours $/ 100 \mathrm{~m}^{3}+100.5 \mathrm{~m}^{3}$ of concrete/100 $\mathrm{m}^{3}$.

By adding internal divisions, the amount of resources per internal measuring unit (100 $\mathrm{m}^{3}$ of concrete) remains constant while the total amount changes depending on the amount of work in cubic meters in each division. Increasing or decreasing the quantity in cubic meters of concrete to be poured causes the total amount of resources to increase or decrease proportionally. In this case, the cost of resources is taken into account when computing the total cost, but not when calculating the cash flow, unless an external scale using time exists. 


\section{3) External Vertical Scales:}

External vertical scales may designate the measuring unit of the y-axis for an orthogonal system. External units should be compatible with all the main physical entities for the whole project. For example, the length of a road in kilometers, which defines the external vertical scale measurement unit of the linear scheduling method, should be compatible with all the main physical entities, or by default the activities.

TABLE 6 EXTERNAL AND INTERNAL VERTICAL SCALE ATTRIBUTES

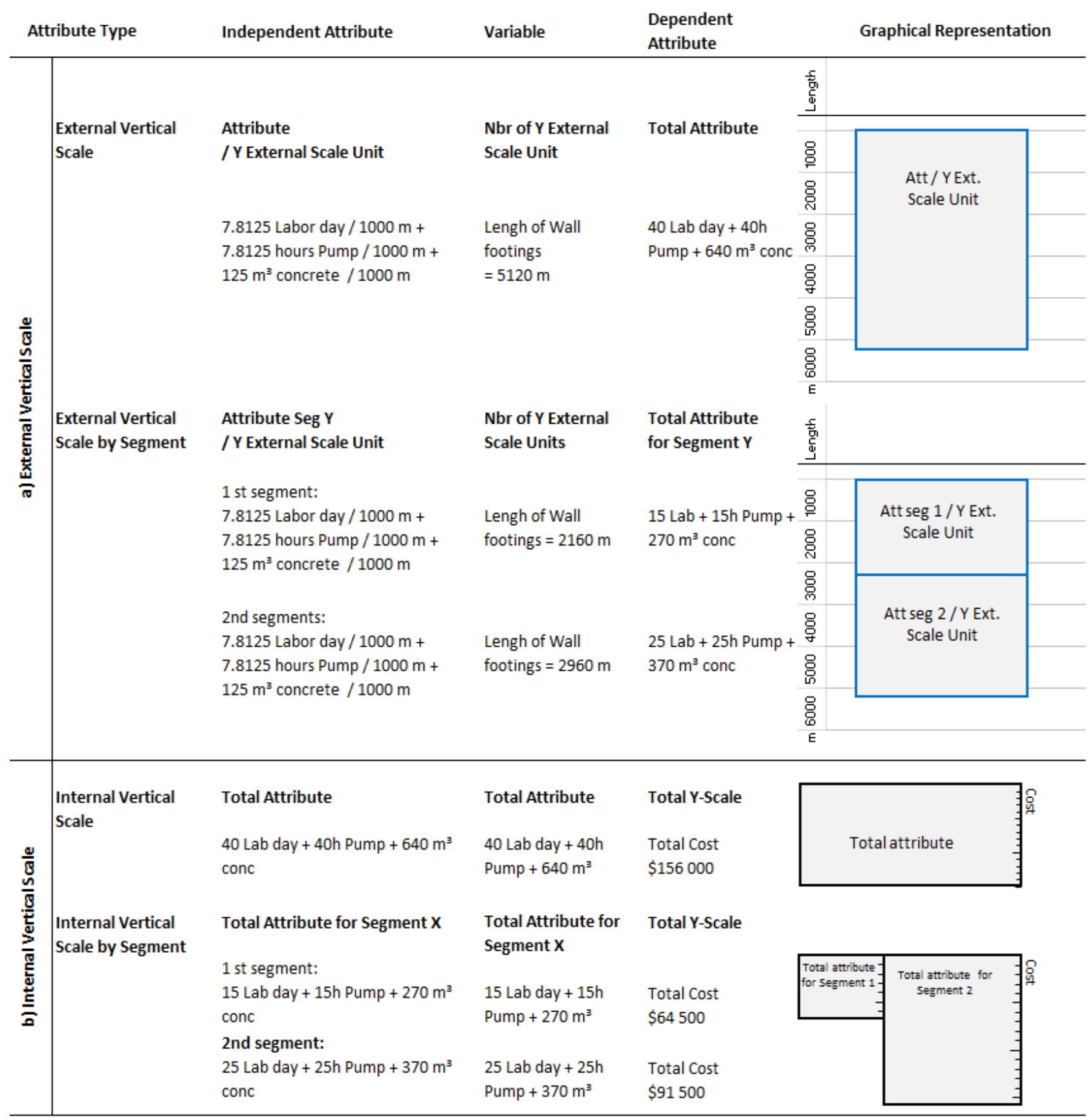

Table 6a shows the allocation methods uses the external vertical scale for the cast-in-place concrete activity. The independent attribute (resources) is assigned to the main physical entity (activity) depending on the external unit of the vertical scale $(\mathrm{km})$. This means assigning an amount of resources to each kilometer $(1000 \mathrm{~m})$. In this table, 7.8125 labor/1000 $\mathrm{m}+$ 7.8125 pump hours $/ 1000 \mathrm{~m}+125 \mathrm{~m}^{3}$ of concrete/1000 $\mathrm{m}$ are assigned to the complete activity. By adding internal divisions, the amounts of human resources (labor), equipment (pump) and materials (concrete) per unit of external measurement (day) remain unchanged.

Attribute/Y External Scale Unit represents the independent attribute, and the total attribute becomes the dependent attribute. This means that increasing or decreasing the length of the wall for the activity or a segment causes the total amount of resources to increase or decrease accordingly. The cost of resources is also taken into account when calculating the total cost. 


\section{4) Internal Horizontal Scales:}

Internal vertical scales (Table 6b) may designate the internal vertical measurement of the physical entities. This means that the cost measurement depends on the resources allocated. With this type, the total attribute represents both the independent attribute and the independent variable. The scale that measures costs becomes the dependent attribute.

In this table, 40 labor days +40 pump hours $+640 \mathrm{~m}^{3}$ of concrete are assigned to the complete activity. With internal divisions, the total amount of resources is distributed to the two segments. The scale that measures costs and represents the dependent attribute is adjusted depending on the amount of resources. Increasing or decreasing the amount of resources causes the measurement unit (cost) to increase or decrease.

\section{Summary of the Attribute Types}

In summary, chronographic logic defines three attribute types: complete attribute, attribute by segment and attribute by scale.

Complete attribute and attribute by segment are used to prevent automatic calculation of allocation or to fix the total amount of allocated resources. These two types of allocation are useful in the case of lump sum contracts and during the project planning phase. In both cases, the total amount of resources is allocated only as an indication or in accordance with the estimate and should not be changed automatically.

The attribute by scale assigns resources to the external or internal scales. These scales can be vertical or horizontal. Scales such as time, cost, work progress, quantity, risk and performance may designate the measurement unit of the orthogonal axes system. In these types of assignments, automatic calculation occurs according to the chosen scale. scale.

With this system, planners can allocate bulk resources to the activity or make an allocation to any external and internal

\section{Links Between Scales}

The links between the external, internal, horizontal and vertical scales show the interactions between the different measurement units. Figs. $1 \mathrm{~b}$ and $1 \mathrm{c}$ and Table 7 demonstrate these interrelations for the cast-in-place concrete activity for the complete and by segment activities. The scales are as follows:

- External horizontal scale: duration in days

- External vertical scale: quantity in linear meters

- Internal horizontal scale: quantity in cubic meters

- Internal vertical scale: cost in dollars

This methodology provides more flexibility than Microsoft Project. In addition, Primavera does not allow the three variables (time, units and units/time) to be set simultaneously; at least one must be changed automatically.

TABLE 7 LINKS BETWEEN THE EXTERNAL, INTERNAL, HORIZONTAL AND VERTICAL SCALES

\begin{tabular}{|c|c|c|c|}
\hline & 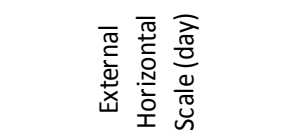 & 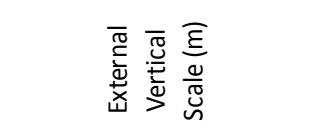 & 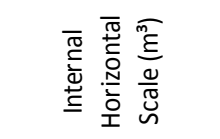 \\
\hline Internal Vertical Scale (\$) & $\begin{array}{c}\text { Cumulative Cost in \$ / } \\
\text { day }\end{array}$ & Unit Cost : \$ / m & Unit Cost : $\$ / \mathrm{m} 3$ \\
\hline $\begin{array}{l}\text { Internal Horizontal Scale } \\
\left(\mathrm{m}^{3}\right)\end{array}$ & $\begin{array}{l}\text { Daily Production } \\
\qquad \mathrm{m}^{3} / \text { day }\end{array}$ & Quantity Relation $\mathrm{m}^{3} / \mathrm{m}$ & \\
\hline External Vertical Scale (m) & $\begin{array}{l}\text { Daily Production } \\
\text { m/day }\end{array}$ & & \\
\hline
\end{tabular}

The interrelations between scales are as follows:

- The two external scales (quantities in linear meters and duration) show the production rate in linear meters and per period (m/day).

- The relation between the internal and external horizontal scales (quantities in cubic meters and time) demonstrates the production rate in cubic meters per period ( $\mathrm{m}^{3} /$ day).

- Both internal and external vertical scales (costs and quantities in linear meters) demonstrate the cost per linear meter $(\$ / \mathrm{m})$.

- The internal vertical scale and the external horizontal scale (cost and time) demonstrate the cash flow or the cumulative cost per period (\$/day). 
- The internal horizontal scale and external vertical scale, both of which depend on quantities in cubic and linear meters, demonstrate the link between these two units (e.g. the excavation quantity in cubic meters for each linear meter of the trench, or $\mathrm{m}^{3} / \mathrm{m}$ ).

- Finally, two internal scales (cost and quantities in cubic meters) show the unit prices per cubic meter $\left(\$ / \mathrm{m}^{3}\right)$.

Note that planners can decide on the interrelation order between these scales. For example, the relation between the cost and quantity in cubic meters shows the unit price per cubic meter, while the inverted interrelation shows the number of cubic meters that could be completed for a unit of cost (here \$100).

\section{TWO APPLICATION EXAMPLES}

To explain the applicability of the allocation system proposed by the Chronographic Method, this section shows resource allocation using two examples: the installation of pipelines and the erection of a partition wall.

\section{A. Installation of Pipelines Example}

The first example concerns the installation of pipelines. This example includes trenching 4280 cubic meters of soil and installing 6000 meters of pipelines. The productivity of the assigned resources for the pipeline installation activity is 1000 linear meters per 2 days.

The bill of quantities measured the trenching activity in cubic meters, while progress in linear meters must be monitored in accordance with the pipeline installation. To do that, the bill of quantities in Fig. 2 shows quantities in cubic meters depending on the soil profile, the width of the excavation, and the depth and slopes of the pipelines (if applicable), as well as the relative quantity in linear meters related to the length of the pipeline installation. The connection between the relative and linked quantities (in this example, the length of the trench and pipelines) can be achieved using a ratio. In this example, the ratio is 1 ( $100 \%$ of the distance of the pipeline).

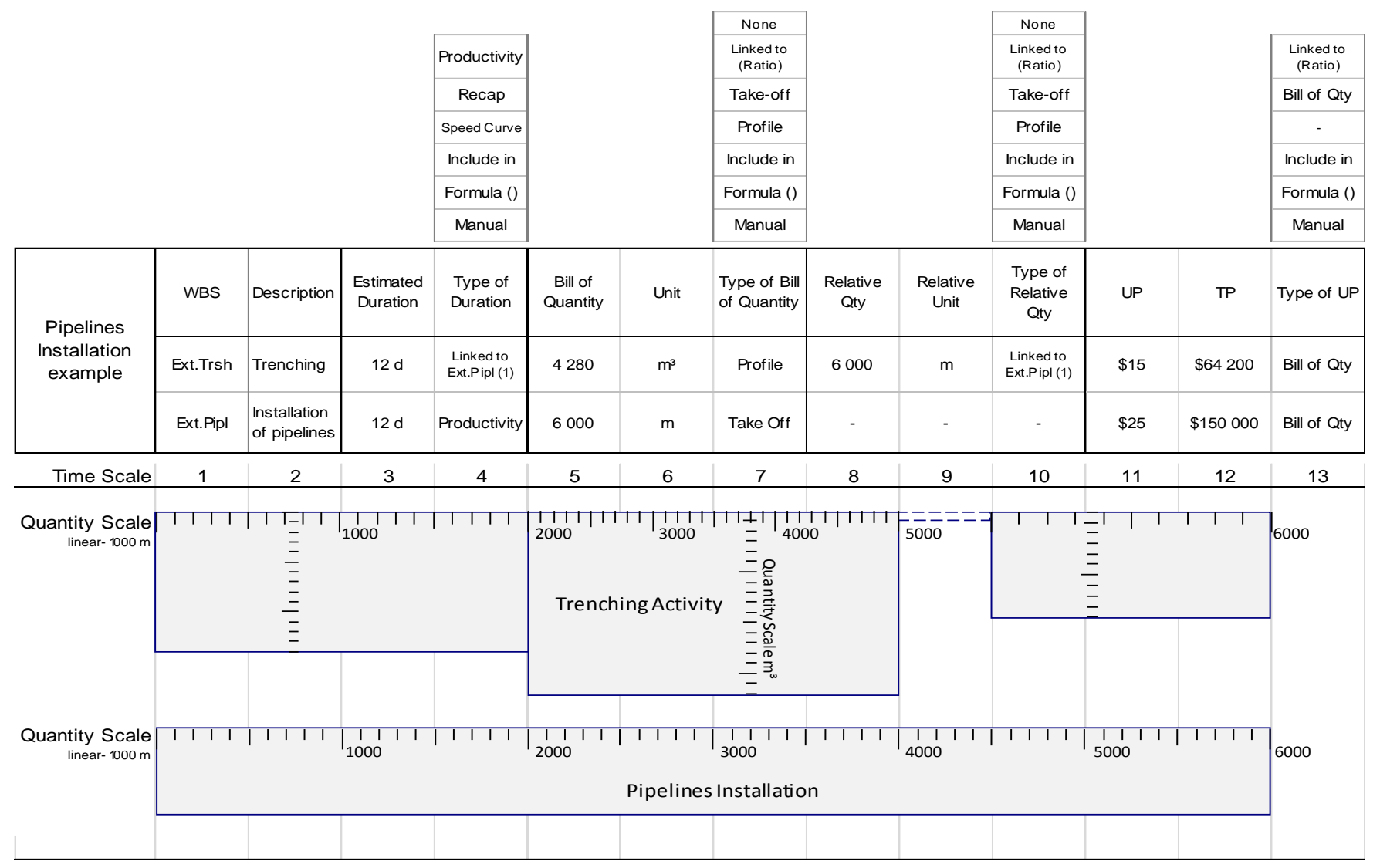

Fig. 2 Pipeline installation example: scales and attributes

This example is modeled with three scales: an external horizontal scale representing time, an internal horizontal scale indicating distance and an internal vertical scale measuring the quantity in cubic meters for each section. An external vertical scale is not used in this example.

Fig. 2 shows two activities, trenching and pipeline installation. The length of the box representing the trenching activity is based on time (duration in days). The internal horizontal scale is adjusted to represent work progress according to the relative quantity in linear meters. The thickness of the boxes depends on the internal vertical scale, which measures the quantity in 
cubic meters for each section based on the production rate of the mechanical shovel. The change in the shovel's production rate is based on the profile and type of soil, but also the progress of pipeline installation. Therefore, the first section of the trenching activity has a length of 2000 linear meters with an excavation quantity of 1400 cubic meters. These quantities are 3000 linear meters and 1800 cubic meters for the second section and 1000 linear meters and 1080 cubic meters for the fourth section. Note that the excavation activity stops in the third section due to a faster production rate of excavation compared to pipeline installation.

\section{B. Erection of a Partition Wall Example}

The second example concerns the erection of a partition wall (Fig. 3). This example uses external and internal horizontal scales for all activities. The external horizontal scale represents time, and the internal horizontal scale represents distance. Some activities have an internal vertical scale that measures the quantity in cubic meters for the internal sections. An external vertical scale is not applied in this example.

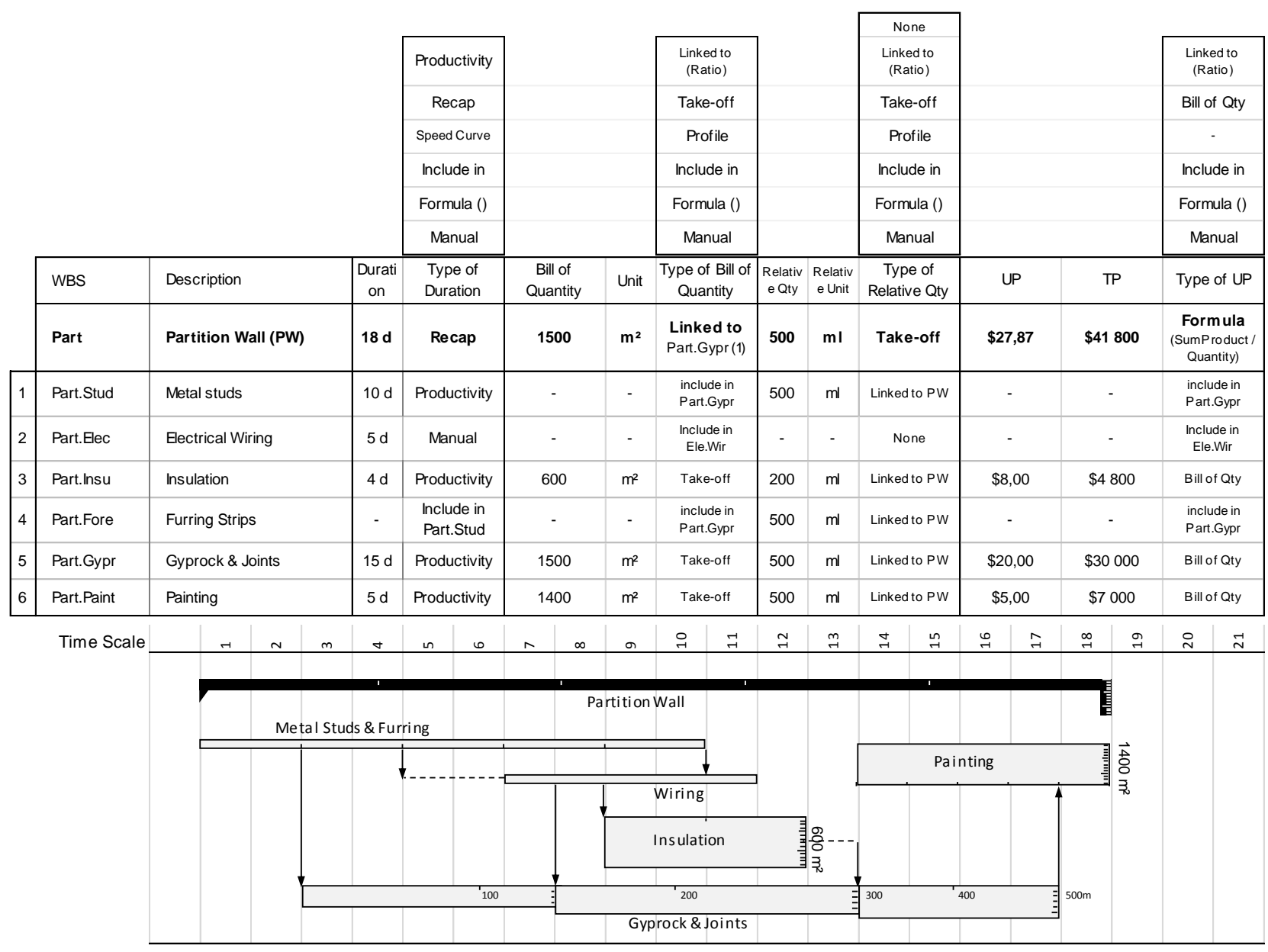

Fig. 3 Erection of a partition wall example: scales and attributes

To erect the wall, six activities are required. Note that the fourth activity, furring strips, is part of the first activity, metal studs. Assignments and constraints are explained below.

1. The metal studs and furring strips (first and fourth activities) are installed by two carpenters producing 50 meters of wall per day. These two carpenters are attributed in the internal horizontal scale depending on the length of the wall. The duration representing the external horizontal scale is then calculated automatically at 10 days. The bill of quantities does not include the amount of metal studs; they are included in the gyprock and joints activity (Part.Gypr). The relative quantity of 500 linear meters is the length of the partition wall. This relative quantity is chosen to facilitate planning and follow up on this activity.

2. Electrical wiring is installed by two electricians working for five days to install all the electrical wire. These two electricians are attributed to the activity as a complete attribute at 10 labor days. The duration of the activity at five days is input manually. The bill of quantity and the unit price are included in Ele.Wir. The relative quantity is hard to estimate, so the planner has chosen the type "None." The electrical wiring activity has two predecessor relational constraints, with the metal studs and furring strips acting as predecessor activities. The first relation (internal-to-start) is linked to the internal horizontal scale for the predecessor activity (200 meters of metal stud installation), and the 
second relation (finish-to-internal) is related to the external horizontal scale of the electrical wiring activity (one day of wiring installation).

3. Only 200 meters of the partition wall are insulated. The insulation is installed by two carpenters producing 50 meters of wall per day. These two carpenters are attributed in the internal horizontal scale depending on the length of the wall. The duration that represents the external horizontal scale is then calculated automatically at four days. The bill of quantities shows the take-off quantity of 600 square meters $(200 \mathrm{~m} \mathrm{x} 3 \mathrm{~m})$. The relative quantity of 200 linear meters represents the part of the partition wall with insulation. This relative quantity is chosen to facilitate planning and follow up on this activity. The insulation activity is linked to an internal-to-start relation on the external horizontal scale for the predecessor activity (two days of wiring installation).

4. The gyprock and joints activity is divided into three sections. The first section is 135 meters long and has neither electrical wires nor insulation. The second section is 165 meters long and has electrical wires but no insulation. The third section is 200 meters long with both electrical wires and insulation. The first two sections are installed by two carpenters producing 28 square meters of wall per day. The last sections are installed by four carpenters who produce 56 square meters of wall per day. The duration of these three sections is then calculated at five days (4.76), six days (5.95) and four days (3.57) respectively. The gyprock and joints activity has three predecessor relational constraints. The first relation (internal-to-start) links the internal horizontal scale of the metal studs and furring strips as a predecessor activity (100 meters of metal stud installation) to the start of the gyprock and joints activity. The second relation (internal-to-internal) connects the external horizontal scales of the predecessor activity (one day of wiring installation) to the internal horizontal scale of the successor activity (135 meters of gyprock installation). The third relation (finish-to-internal) relates the end of the insulation activity to the internal horizontal scale of the successor activity (300 meters of gyprock installation).

5. The last activity, painting, is executed by two painters producing 100 meters of wall per day. These two painters are attributed to the internal horizontal scale depending on the length of the wall. The duration represented on the external horizontal scale is then calculated automatically at five days. The bill of quantities shows the take-off quantity of 1400 square meters $(500 \mathrm{~m} \times 2.8 \mathrm{~m})$. The relative quantity of 500 linear meters is the length of the partition wall. This relative quantity is chosen to facilitate planning and follow up on this activity. The painting activity has a finish-tointernal relation relating the end of the gyprock and joints activity to the internal horizontal scale of the successor activity (400 meters of painting).

\section{Different Types of Duration, Quantities and Unit Prices}

Figs. 2 and 3 show the different types of duration, quantities and unit prices. Schedulers may impose manual values or apply all forms of formulas or links to each of these elements. Here is an explanation of these choices.

1. The duration type of activity could be:

- $\quad$ calculated using the productivity of the assigned resources

- $\quad$ recapitulative depending on schedule calculations, taking into consideration the subactivity constraints

- $\quad$ related to equipment speed variations; by establishing a speed curve for a dozer depending on the thickness of the base layer of a road project

- $\quad$ included in the duration of another activity; in this case, no duration is attributed to this activity

- a formula

- a manually imposed duration

2. The quantity type (Bill or Relative) could be:

- $\quad$ none, to indicate that no quantities have to be attributed

- linked as a ratio of a second activity's quantity, depending on other quantities; for example, the quantity of backfill can be a function of the excavation quantity

- $\quad$ linked to the take-off quantity

- $\quad$ calculated from the soil profile (e.g. landscaping activity)

- $\quad$ included in another quantity; for example, metal studs could be included in the bill of quantity for the partition wall installation

- a formula

- a manually imposed duration

3. The unit price types could be:

- linked as a ratio of a second unit price; for example, the unit price of formwork could be a function (the double) of the unit price of formwork for the slab

- $\quad$ from the bill of quantity; for example, an estimated price or a unit price received from a subcontractor

- $\quad$ included in another unit price; for example, metal studs could be included in the unit price of the partition wall 


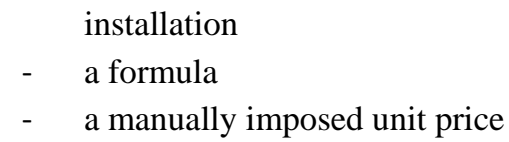

\section{CONCLUSIONS}

It is indisputable that the success of projects necessarily involves efficiently managing resources. Allocating, leveling and optimizing resources are not considered a simple task, especially if the existing software does not allow for flexible approaches that meet all needs. The lack of consensus in the industry indicates that there is no universal method for resource management. Several methods exist for resource allocation, and scheduling software uses a multitude of these methods. Each software program or scheduling method uses its own language and logic for assigning resources to activities. Each method has advantages and limitations.

To resolve these shortcomings, this paper proposes a new chronographic allocation methodology. With internal divisions and internal, external, vertical and horizontal scales, the new attribute method allows for creation of all kinds of attributes, from bulk allocation to any type of external and internal scale attribute. The proposed chronographic allocation methodology puts forward a complete and more realistic method by defining three new attribute methods: complete attribute, attribute by segment and attribute by scale. The links between scales could also show interactions between different measurement units and offer several types of durations, quantities, and costs for increased flexibility, and to resolve the limitations of existing methods.

Some restrictions may limit the use of the proposed method above all, the requirement that commercial software takes possession and the need for more advanced training. Despite this, this method remains attractive and offers a flexible allocation method that meets the needs of planners and resolves the limitations of existing methods. This method may also positively impact the construction industry by introducing a more complete and realistic allocation methodology and by helping planners assign resources in a clear and comprehensible manner. In conclusion, the Chronographic Modeling Attribute Method is an appropriate decision-making tool for project management.

\section{REFERENCES}

[1] B. Ashuri and M. Tavakolan, "Fuzzy enabled hybrid genetic algorithm-particle swarm optimization approach to solve TCRO problems in construction project planning," Journal of Construction Engineering and Management, vol. 138(9), pp. 1065-1074, 2012. doi: 10.1061/(ASCE)CO.1943-7862.0000513.

[2] J. D. Caprace, C. Petcu, M. G. Velarde, and P. Rigo, "Optimization of shipyard space allocation and scheduling using a heuristic algorithm," Journal of Marine Science and Technology (Japan), vol. 18(3), pp. 404-417, 2013. doi: 10.1007/s00773-013-0217-2.

[3] L.-S. Kang, H.-S. Moon, C.-H. Min, S.-K. Kim, and H. S. Kim, "Developing an active resource allocation algorithm considering resource supply and demand in a construction site," KSCE Journal of Civil Engineering, vol. 19(1), pp. 17-27, 2014. doi: 10.1007/s12205-013-0203-6.

[4] S. Asgari, A. Afshar, and K. Madani, "Cooperative game theoretic framework for joint resource management in construction," Journal of Construction Engineering and Management, vol. 140(3), 2014. doi: 10.1061/(ASCE)CO.1943-7862.0000818.

[5] Y. Zhou, L. Ding, X. Wang, M. Truijens, and H. Luo, "Applicability of 4D modeling for resource allocation in mega liquefied natural gas plant construction,” Automation in Construction, vol. 50(C), pp. 50-63, 2015. doi: 10.1016/j.autcon.2014.10.016.

[6] B. Ashuri and M. Tavakolan, "Shuffled frog-leaping model for solving time-cost-resource optimization problems in construction project planning," Journal of Computing in Civil Engineering, vol. 29(1), 2015. doi: 10.1061/(ASCE)CP.1943-5487.0000315.

[7] S.-M. Chen, F. H. Griffis, P.-H. Chen, and L.-M. Chang, "Simulation and analytical techniques for construction resource planning and scheduling," Automation in Construction, vol. 21(1), pp. 99-113, 2012. doi: 10.1016/j.autcon.2011.05.018.

[8] S. Min and H. H. Einstein, "Resource scheduling and planning for tunneling with a new resource model of the Decision Aids for Tunneling (DAT)," Tunnelling and Underground Space Technology, vol. 51, pp. 212-225, 2016. doi: 10.1016/j.tust.2015.10.038.

[9] M.-F. F. Siu, M. Lu, and S. Abourizk, "Resource supply-demand matching scheduling approach for construction workface planning," Journal of Construction Engineering and Management, vol. 142(1), 2016. doi: 10.1061/(ASCE)CO.1943-7862.0001027.

[10] L. Zhang, X. Zou, and Z. Kan, "Improved strategy for resource allocation in repetitive projects considering the learning effect," Journal of Construction Engineering and Management, vol. 140(11), 2014. doi: 10.1061/(ASCE)CO.1943-7862.0000896.

[11] A. Francis and E. T. Miresco, "Decision support for project management using a chronographique approach," Journal of Decision Systems, Special issue JDS-DM in UCE: Decision Making in Urban and Civil Engineering, vol. 11(3-4), pp. 383-404, 2002. doi.org/10.3166/jds.11.383-404.

[12] A. Francis and E. T. Miresco, "A chronographic method for construction project planning," Canadian Journal of Civil Engineering (CSCE), vol. 33(12), pp. 1547-1557, 2006. doi: 10.1139/106-148.

[13] A. Francis and E. T. Miresco, "Simulation of execution alternatives using chronographic scheduling logic," Journal of Civil Engineering and Science (JCES), vol. 5(1), pp. 1-8, 2016. doi: 10.5963/JCES0501001.

[14] A. Francis, "Comparing time and quality scales for relatinship and float calculations," Procedia Engineering, vol. 164, pp. 49-56, 2016. doi.org/10.1016/j.proeng.2016.11.591.

[15] A. Francis, "Simulating uncertainties in construction projects with chronographical scheduling logic," Journal of Construction Engineering and Management, vol. 143(1), pp. 1-14, 2017. doi: 10.1061/(ASCE)CO.1943-7862.0001212. 